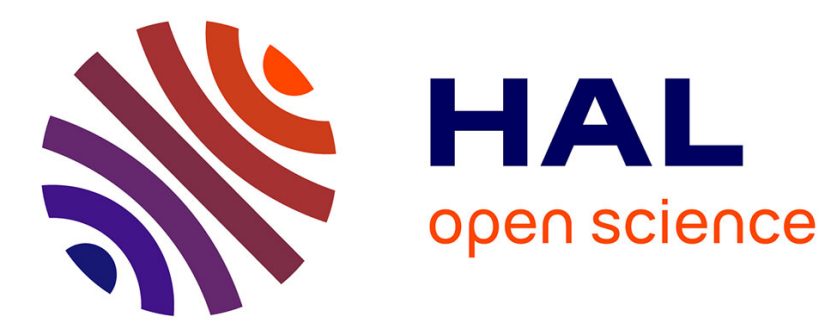

\title{
Response of a Josephson receiver with a Nb3 Sn ribbon contact at $70 \mathrm{GHz}$
}

S. Gygax, W. Zingg

\section{To cite this version:}

S. Gygax, W. Zingg. Response of a Josephson receiver with a Nb3 Sn ribbon contact at $70 \mathrm{GHz}$. Revue de Physique Appliquée, 1974, 9 (1), pp.269-271. 10.1051/rphysap:0197400901026900 . jpa-00243752

HAL Id: jpa-00243752

https://hal.science/jpa-00243752

Submitted on 1 Jan 1974

HAL is a multi-disciplinary open access archive for the deposit and dissemination of scientific research documents, whether they are published or not. The documents may come from teaching and research institutions in France or abroad, or from public or private research centers.
L'archive ouverte pluridisciplinaire HAL, est destinée au dépôt et à la diffusion de documents scientifiques de niveau recherche, publiés ou non, émanant des établissements d'enseignement et de recherche français ou étrangers, des laboratoires publics ou privés. 


\title{
RESPONSE OF A JOSEPHSON RECEIVER WITH A $\mathbf{N b}_{3} \mathrm{Sn}$ RIBBON CONTACT AT $70 \mathrm{GHz}$
}

\author{
S. GYGAX $(*)$ and W. ZINGG
}

Institut de Physique Expérimentale, DPMC

Université de Genève, Genève, Suisse

\begin{abstract}
Résumé. - La construction d'un SQUID fonctionnant comme mélangeur et oscillateur local à $4 \mathrm{~mm}$ de longueur d'onde est décrite en détail. Le signal détecté dépend fortement de la fréquence. Son comportement en fonction de la puissance microonde incidente indique qu'il s'agit d'un détecteur quadratique à faible niveau et d'un détecteur linéaire à niveau élevé de puissance microonde. La sensibilité atteinte est de $10^{-15} \mathrm{~W}$.

Abstract. - The construction of a R-SQUID which acts as a mixer and local oscillator in the $4 \mathrm{~mm}$ range is described in detail. A strong frequency dependence of the detected signal is found and its dependence on the incident microwave power indicates that the device acts as a square law detector for low power levels and as a linear detector for the higher ones. A sensitivity of $10^{-15} \mathrm{~W}$ was achieved.
\end{abstract}

In a recent article by Fife and Gygax [1] the response of a resistive SQUID to millimeter radiation has been reported in some detail. While this work provided extensive information about its mode of operation, the frequency response, the line shape, the influence of the $\mathrm{Nb}$ contacts on the spectrum, etc., it was clear that one of the most interesting questions remained to be dealt with : the ultimate sensitivity to microwave and submillimeter radiation. Due to the reasons for investigating this kind of detector an essentially open structure had been chosen incorporating a crude split horn. The sensitivity around $70 \mathrm{GHz}$ was reported to be $10^{-12} \mathrm{~W}$ with a post-detection bandwidth of $1 \mathrm{~Hz}$.

We report here on a new structure which provides substantially improved coupling to radiation and give the results of a study of the frequency and power dependence of the detected signal around $70 \mathrm{GHz}$.

We have made essentially three major changes in the design of the R-SQUID (see Fig. 1). First, the
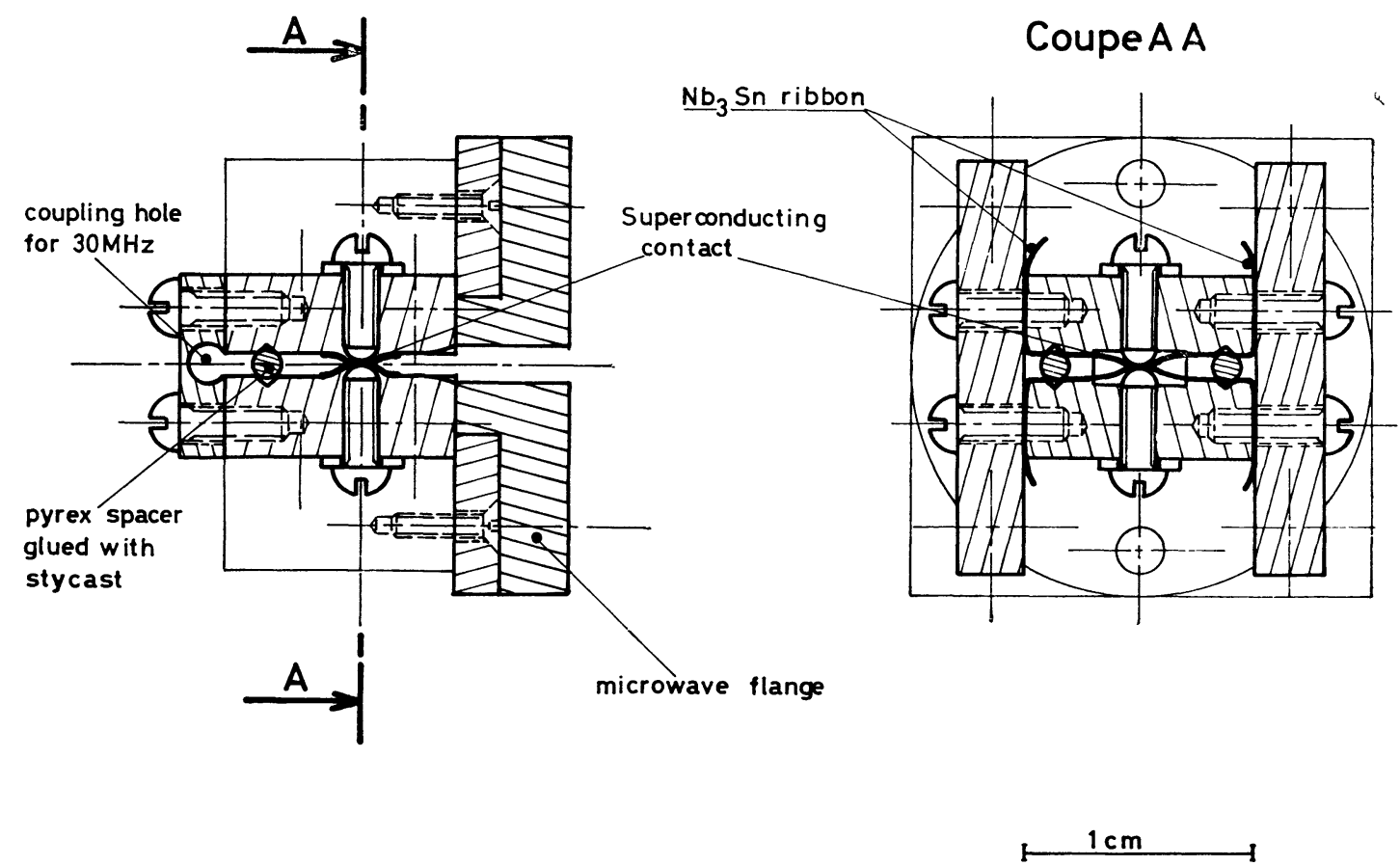

FIG. 1. - Sectional view of R-SQUID. Unless otherwise indicated the material used is stainless steel. 
whole structures, except the superconducting contact, was made out of resistive material (stainless steel). The slit spacers are pyrex rods or tubes and the parts were glued together with stycast epoxy. Second, the superconducting contact was provided by a pair of $\mathrm{Nb}_{3} \mathrm{Sn}$ ribbons soldered onto the sides of the two central stainless steel parts. The contact was adjusted by two rounded-off stainless steel 080 screws. This arrangement presumably increases the coupling of the contact area to radiation because of its smoother geometry compared with screw contacts. This was confirmed by the much reduced sensitivity when $\mathrm{Nb}$ screws were used in the same structure rather than the $\mathrm{Nb}_{3} \mathrm{Sn}$ ribbon. Commercially available $\mathrm{Nb}_{3} \mathrm{Sn}$ ribbon usually used for superconducting magnets were prepared in such a way that the cover sandwich of $\mathrm{Sn} / \mathrm{Cu} / \mathrm{Sn} / \mathrm{Ag}$ was chemically or mechanically removed on one side of the tape to expose the $\mathrm{Nb}_{3} \mathrm{Sn}$. The other side still allowed soldering to the stainless steel body and to current leads. Third, the resistive SQUID was shaped in the form of a waveguide. The front parts of the two central sections had a tapered cut-out which fitted on a standard $4 \mathrm{~mm}$ waveguide on one side and to the slit width on the other. From there on the $\mathrm{Nb}_{3} \mathrm{Sn}$ ribbon provides the final taper to the contact area. The sides of the structure are closed by stainless steel plates. Those as well as the screws and the microwave flange in front had to be isolated electrically to the top central section by thin mica sheets in order to prevent shorting out the intermediate frequency signal. This $I F$ signal was picked up by a coil in the hole of the back part. This part was removable, which allowed us to monitor the contact resistance and investigate the possibility of adjusting the contact at room temperature and recycling the structure to liquid helium temperature repeatedly. We have not yet made a systematic study of sensitivity as a function of room temperature contact resistance. In most of our measurements we utilized a worm gear arrangement which allowed an adjustment at liquid helium temperatures.

A klystron, tunable between 68 and $71 \mathrm{GHz}$ provided the microwave radiation which passed a series of attenuators before entering the R-SQUID structure. Due to the high sensitivity of the device any radiation leakage bypassing the attenuators had to be carefully eliminated. The mode of operation of the R-SQUID and the electronics were basically the some as described in the earlier paper [1]. The contact is thought to behave as a mixer and local oscillator, whose frequency is determined by the current through the resistive part. The sideband is detected at a constant intermediate frequency $(30 \mathrm{MHz})$ magnetically coupled to a tank circuit.

Most features of the detected signal showed the same behaviour as reported earlier [1]. We again found that injection of $\mathrm{rf}$ into the tank circuit amplified the signal while it also broadened the line. Furthermore harmonics, subharmonics and spurious lines appeared when the contact was made too strong. A new feature appeared however when we studied the frequency dependence of the detected signal on the microwave frequency. While the old open structure had essentially the same sensitivity over the large frequency range studied, we find a very strong frequency dependence with the waveguide structure (Fig. 2). The measurements were taken in such a way that the power entering the R-SQUID was kept constant while changing the frequency of the klystron. As expected the waveguide structure of the R-SQUID results in pronounced maximas and minimas for the detected amplitude $A$. This result indicates that the advantages of our waveguide structure are offset somewhat by the strong frequency dependence. Unless some provision for tuning is incorporated in the device it will work well only at selected frequencies. Due to the limited frequency range of our study we do not know if the highest sensitivity is obtained outside the 68 to $71 \mathrm{GHz}$ range or happens to be at $68.92 \mathrm{GHz}$ were all the subsequent measurements were taken.

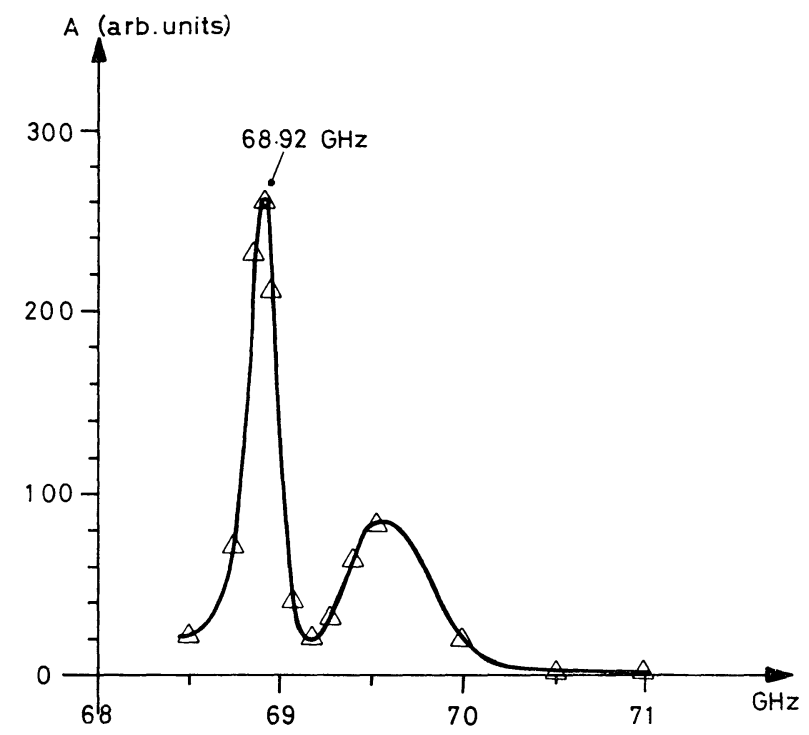

Fig. 2. - Frequency dependence of the detected signal $\boldsymbol{A}$.

We also investigated the dependence of the detected signal amplitude on the incident microwave power $P$ which is shown in figure 3 . This log-log plot incorporates two runs in between which the structure was completely taken apart and the $\mathrm{Nb}_{3} \mathrm{Sn}$ ribbons replaced. The data shows that with similar rf injection a good contact gives about the same signal amplitude from run to run. As can be seen from figure 3 the initial dependence of the signal amplitude $A$ on the microwave power $P$ is linear going over to a $P^{1 / 2}$ dependence at higher power levels. In terms of a model for the superconducting contact as a voltage biased Josephson junction one may assume that the incident microwave induces a voltage $v_{\mathrm{s}}$ across the junction in addition to the dc voltage. This will result in an ac Josephson current at the IF frequency of amplitude

$$
J_{1}\left(2 \mathrm{e} v_{\mathrm{s}} / h f_{\mathrm{s}}\right) \text {. }
$$




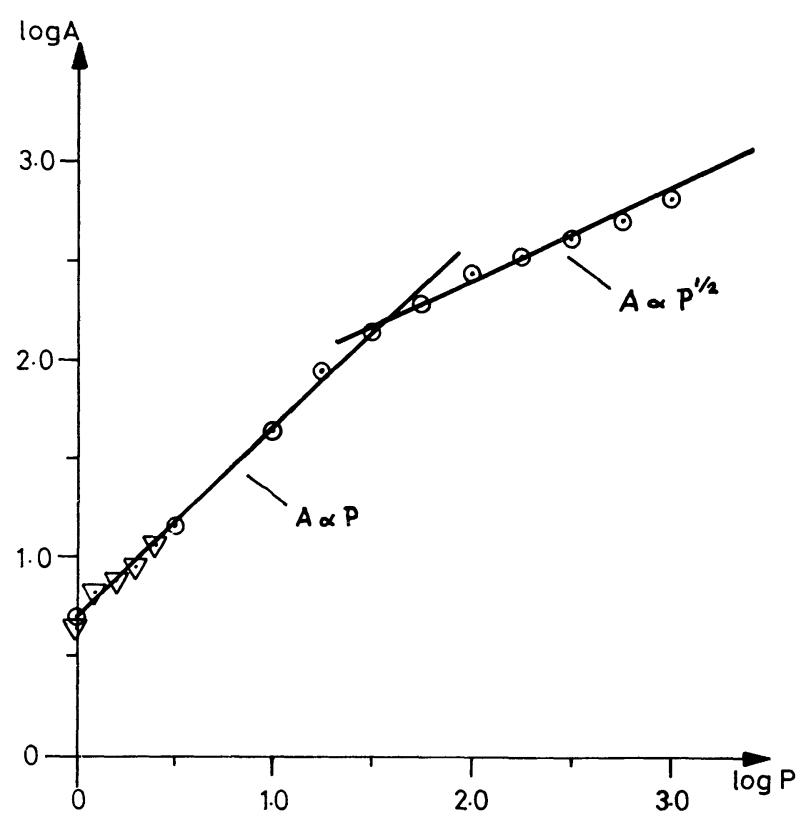

FIG. 3. - Variation of the detected signal amplitude $A$ with the power level of the incident microwave radiation at $68.92 \mathrm{GHz}$. The two sets of data were obtained in two different runs with different contacts.

For very small signal amplitudes $v_{\mathrm{s}}$ the Bessel function $J_{1}$ can be replaced by its argument and the detected signal $A$ should be proportional to the incident signal amplitude. One would therefore expect a linear detector, or $A \propto P^{1 / 2}$. However as pointed out by Richards, Auracher and van Duzer [2] the input signal has to be strong enough to synchronize the Josephson oscillator in the presence of noise. Thermal noise in the bias resistor $R_{\mathrm{B}}$ gives rise to an effective Josephson line width of

$$
\Delta f=\frac{4 \pi k T R_{\mathrm{B}}}{\varphi_{0}^{2}} \simeq 6.5 \times 10^{6} R_{\mathrm{B}} T \quad(\mathrm{MKS}) .
$$

The position of the $70 \mathrm{GHz}$ line on the current axis implies a resistance $R_{\mathrm{B}}=2.3 \mathrm{~m} \Omega$ of the R-SQUID structure and a $\Delta f \sim 65 \mathrm{MHz}$. The observed linewidth was much larger and typically about $1 \mathrm{GHz}$. We attribute this to the fact that for this study we took an ordinary power supply for the current with no special precautions for stability and rf shielding and that the experiment was performed in a set of glass dewars with no shields. The power required for synchronization by the incident radiation is given by [2] :

$$
P \geqslant \Delta f k T
$$

Using $\Delta f \sim 1 \mathrm{GHz}$ one arrives at $P \geqslant 5.8 \times 10^{-14} \mathrm{~W}$. From figure 3 we notice that the $A \propto P^{1 / 2}$ dependence, or linear detector regime $A \propto v_{\mathrm{s}}$, starts at $\sim 16 \mathrm{~dB}$ above the initial power setting which was such that the signal was a few times larger than the noise. With the above minimum synchronization power and the position of the break in figure 3 one arrives at a sensitivity of $\sim 10^{-15} \mathrm{~W}$. For low signal power the R-SQUID acts as a square law detector $\left(A \propto v_{\mathrm{s}}^{2}\right.$, or $A \propto P$ ), at higher power levels as a linear detector $\left(A \propto v_{\mathrm{s}}\right.$, or $\left.A \propto P^{1 / 2}\right)$.

We also measured the sensitivity directly using a series of attenuators in the waveguide system. Due to the high attenuation required $(\sim 120 \mathrm{~dB})$ those measurements were not very precise. For a typically good contact, giving a good signal at the fundamental and no harmonics, a conservative estimate for the sensitivity of somewhat better than $10^{-15} \mathrm{~W}$ was consistently obtained. The post-detection bandwidth for these measurements was set at $1 \mathrm{~Hz}$.

Acknowledgments. - We thank the members of the DPMC for their enthusiastic cooperation in providing the necessary equipment and technical help. One of us (S. G.) would like to express his gratitude for the kind hospitality he received in the Institut de Physique Expérimentale.

\section{References}

[1] Fife, A. A. and Gygax, S., J. Appl. Phys. 43 (1972) 2391.

[2] Richards, P. L., Auracher, F., and van Duzer, T., Proc. IEEE 61 (1973) 36. 